\title{
Article \\ Cyclodextrins-in-Liposomes: A Promising Delivery System for Lippia sidoides and Syzygium aromaticum Essential Oils
}

\author{
Iara Baldim ${ }^{1,2} \mathbb{D}$, Andressa M. Oliveira ${ }^{1}$, Eliana B. Souto ${ }^{2, *(\mathbb{D}}$ and Wanderley P. Oliveira ${ }^{1, *(1)}$ \\ 1 School of Pharmaceutical Sciences of Ribeirão Preto, University of São Paulo, \\ Ribeirão Preto 14040-903, SP, Brazil; iara.baldim@usp.br (I.B.); andressa.matias.oliveira@usp.br (A.M.O.) \\ 2 CEB-Centre of Biological Engineering, University of Minho, Campus de Gualtar, 4710-057 Braga, Portugal \\ * Correspondence: eliana.souto@ceb.uminho.pt (E.B.S.); wpoliv@fcfrp.usp.br (W.P.O.)
}

Citation: Baldim, I.; Oliveira, A.M.; Souto, E.B.; Oliveira, W.P. Cyclodextrins-in-Liposomes: A Promising Delivery System for Lippia sidoides and Syzygium aromaticum Essential Oils. Life 2022, 12, 95. https://doi.org/10.3390/life12010095 Academic Editors: Pasquale Stano and Othmane Merah

Received: 7 December 2021

Accepted: 9 January 2022

Published: 10 January 2022

Publisher's Note: MDPI stays neutral with regard to jurisdictional claims in published maps and institutional affiliations.

Copyright: (C) 2022 by the authors. Licensee MDPI, Basel, Switzerland. This article is an open access article distributed under the terms and conditions of the Creative Commons Attribution (CC BY) license (https:// creativecommons.org/licenses/by/ $4.0 /)$.

\begin{abstract}
Biological activity of essential oils (EOs) has been extensively reported; however, their low aqueous solubility, high photosensitivity, and volatility compromise a broad industrial use of these compounds. To overcome these limitations, we proposed a nanoencapsulation approach to protect EOs, that aims to increase their stability and modulate their release profile. In this study, drug-incyclodextrin-in-liposomes encapsulating two essential oils (Lippia sidoides and Syzygium aromaticum) and their respective major compounds (thymol and eugenol) were produced by ethanol injection and freeze-dried to form proliposomes and further physicochemically characterized. Liposomes showed high physical stability over one month of storage at $4{ }^{\circ} \mathrm{C}$, with slight changes in the mean size, polydispersity index (PDI), and zeta potential. Reconstituted proliposomes showed a mean size between 350 and $3300 \mathrm{~nm}$, PDI from 0.29 to 0.41 , and zeta potential between -22 and $-26 \mathrm{mV}$. Differential scanning calorimetry and X-ray diffraction of proliposomes revealed a less-ordered crystalline structure, leading to high retention of the major bioactive compounds (between $73 \%$ and $93 \%$ for eugenol, and $74 \%$ and $84 \%$ for thymol). This work highlights the advantages of using drug-in-cyclodextrin-in-liposomes as delivery systems to retain volatile compounds, increasing their physicochemical stability and their promising potential to be utilized as carriers in products in the pharmaceutical, food, and cosmetic industries.
\end{abstract}

Keywords: proliposomes; cyclodextrins; thymol; eugenol; Lippia sidoides; Syzygium aromaticum

\section{Introduction}

Essential oils (EOs) are known for showing a multitude of biological effects due to their variable terpene, terpenoid, and phenolic contents [1]. Numerous studies have highlighted the properties of EOs as antimicrobial [2-4], antiviral [5], pesticide [6], larvicidal [7], anti-inflammatory [8], and antioxidant [9] agents, among others. These compounds are widely accepted by consumers because of their natural status and safety profile [1]. In particular, the essential oils of Lippia sidoides (LEO), popularly known as pepper rosemary, and clove (Syzygium aromaticum) (CEO) have been extensively studied for their antimicrobial effects $[2,10]$. These EOs are rich in thymol and eugenol, respectively, compounds that are linked to their antimicrobial activity. Despite the high potential use as active ingredients, EOs are volatile liquids, very sensitive to environmental variations; and susceptible to degradation, especially when exposed to light, oxygen, heat, and humidity. To widen their applicability, encapsulation technologies have been proposed [2,11,12].

Liposomes have been widely used as drug delivery systems for sustained-release purposes. They are non-toxic lipid-based carriers consisting of concentric vesicles formed by one or more phospholipid bilayers $[13,14]$. The amphiphilic character of phospholipid molecules offers the liposomes the ability to encapsulate both hydrophilic and lipophilic compounds, being an attractive approach for the loading of EOs [15]. In contrast, problems such as oxidation and hydrolysis of the phospholipids lead to leakage of the encapsulated active ingredient and aggregation of the vesicles [16]. Moreover, the entrapment of 
lipophilic compounds is limited to the inner hydrocarbon chains of the lipid bilayers, and can thus be rapidly released from the liposomes [17]. Cyclodextrins (CDs), on the other hand, are suitable to form inclusion complexes with a large variety of molecules due to their ability to establish weak intermolecular interactions and increase the solubility of lipophilic compounds [18], both in the solid and aqueous state $[19,20]$. This process has, as its main advantages, high encapsulation efficiency and long retention time. The possibility of transforming liquid compounds into crystalline forms, masking possible odors and unpleasant tastes, and increasing the physicochemical stability of volatile compounds are other notable advantages [20]. It is also noteworthy that CDs are generally recognized as safe by the United States Food and Drug Administration (US FDA) agency for use as protectants and additives in food products, and also as flavor carriers [20].

Beta-cyclodextrin $(\beta-C D)$ is a cyclic polysaccharide, which presents a hydrophilic external surface and a hydrophobic internal cavity [6]. Its derivative 2-hydroxypropyl- $\beta$ cyclodextrin $(\mathrm{HP}-\beta-\mathrm{CD})$ has attracted interest due to its improved ability to form inclusion complexes, greater water solubility, and lower toxicity toward biological membranes [21]. Furthermore, the presence of CDs in the aqueous core of liposomes preserves the integrity of the membrane without affecting the characteristics of the liposomes. Hence, drug-incyclodextrin-in-liposomes (DCL) can be an interesting approach, since it combines the advantages of both carriers, cyclodextrins, and liposomes, in providing controlled drug release [21]. DCLs are based on the entrapment of $\mathrm{CD} /$ drug inclusion complex into the inner cavity of liposomes. This technique allows an increase in the solubility of the bioactives and in the stability of the vesicles; being particularly suitable for the delivery of volatile compounds [20], like essential oils. Additionally, compared to conventional liposome production methods, the double loaded technique provides rapid release of the actives from the outer phospholipid bilayer, as well as prolonged release due to the presence of the inclusion complex in the inner aqueous core [22].

To ensure the stability and increase the shelf-life of liposomes containing volatile compounds, freeze-drying can be used very conveniently. Such drying processes occur at low temperatures and without the presence of water in the liquid form, favoring both greater stability and the retention of bioactives. The particulate-based forms, known as proliposomes, generate liposomal suspension upon hydration under appropriate stirring conditions $[23,24]$.

Although many recent studies have used DCL as carriers for encapsulating lipophilic compounds $[18,21,25,26]$, few attempts have been made on the encapsulation of more than one essential oil in the same structure. This is a challenging strategy as EOs have a complex and varied composition, including terpenes, phenylpropenes, and oxygenated compounds. There can be over a hundred different compounds in a single EO [1]. Despite presenting challenges in the production stage, the inclusion of more than one bioactive (or more than one EO) has the possibility of a producing a synergistic effect and can potentially reduce the dose required for single drug usage with increased drug-efficacy, and subsequently lower drug toxicity.

Therefore, the purpose and the novelty of the present study is the development of proliposomes of DCLs combining two EOs (or the combination of their major isolated bioactives). The proliposomes of DCLs were prepared by the double loading technique, where the bioactives were added both in the organic phase and in their inclusion complex in the aqueous phase. We used different bioactives combinations (both Lippia sidoides and clove essential oils in combination and isolated, and their respective major components, thymol, and eugenol). Based on its remarkable antimicrobial activity, the pepper rosemary and clove EOs, and their major compounds, thymol, and eugenol, were chosen as models for this study. Proliposomes were obtained by freeze-drying, and their reconstituted liposomes were characterized concerning the mean hydrodynamic diameter, polydispersity index, zeta potential, differential scanning calorimetry, X-ray diffraction, and retention of the bioactive major compounds. 


\section{Materials and Methods}

\subsection{Materials}

2-Hydroxypropyl- $\beta$-cyclodextrin (HP- $\beta$-CD) was supplied by Roquette (Lestrem, France), and hydrogenated soybean Phospholipon $90 \mathrm{H}$ was purchased from Lipoid $\mathrm{GmbH}$ (Ludwigshafen am Rhein, Germany). Eugenol (Eug), eugenyl acetate (Eug-Ac), thymol, absolute ethanol, cholesterol, and methanol-HPLC grade were purchased from SigmaAldrich (Darmstadt, Germany). CEO (essential oil from Syzygium aromaticum), having as the main compounds Eug (86.89\%), Eu-Ac (2.91\%), trans-caryophyllene (9.04\%), $\alpha$ caryophyllene $(0.97 \%)$, and the butyl acetate $(0.09 \%)$, was bought from a clove essential oil producer located in Valença (BA, Brazil). LEO (essential oil from Lippia sidoides), having thymol $(68.5 \%)$, p-cimeno $(9.43 \%)$, trans-caryophyllene $(7.72 \%), \beta$-myrcene $(2.84 \%), \gamma$ terpinene $(2.71 \%), \alpha$-terpinene $(1.16 \%)$, and thymol methyl ether $(0.97 \%)$ as the main compounds, was obtained from PRONAT (Produtos Naturais Ltd.a, Recife, PE, Brazil).

\subsection{Preparation of Drug-in-CD-in-Liposomes}

Liposomal formulations were prepared by the ethanol injection method adapted from Sebaaly et al. [17]. Briefly, the aqueous phase, consisting of the inclusion complexes of HP$\beta-C D$ with bioactives was prepared by dissolving HP- $\beta-C D$ in ultra-pure water and adding the bioactive (CEO and/or LEO, eugenol, and thymol). This solution was stirred for $24 \mathrm{~h}$ at $25 \pm 2{ }^{\circ} \mathrm{C}$. Subsequently, the organic phase was prepared by dissolving Phospholipon $90 \mathrm{H}$ and cholesterol in absolute ethanol under magnetic stirring and heated at $55^{\circ} \mathrm{C}$ (above the transition temperature of the phospholipids), when the previously heated bioactive (CEO, LEO, thymol, and Eug) was added. A peristaltic pump was used to inject the organic phase into the aqueous phase at a flow rate of $1 \mathrm{~mL} / \mathrm{min}$. The obtained dispersion was kept under magnetic stirring for $15 \mathrm{~min}$, at room temperature. Finally, ethanol and some of the water were removed by rotary evaporation at $45^{\circ} \mathrm{C}$ (Rotavapor Fisatom model 802, Perdizes, SP, Brazil). The storage of all dispersions prepared took place in a dark room at $4{ }^{\circ} \mathrm{C}$. Table 1 shows the composition of the produced EOs-in-cyclodextrin-in-liposomes.

Table 1. Composition of the EOs-in-cyclodextrin-in-liposome systems.

\begin{tabular}{cccccc}
\hline \multirow{2}{*}{ Phase } & Component (g) & \multicolumn{4}{c}{ Formulation } \\
\cline { 3 - 6 } & & CDC & CDL & CDCL & CDET \\
\hline \multirow{3}{*}{ Organic } & Phospholipon 90H & 0.4 & 0.4 & 0.4 & 0.4 \\
phase & Cholesterol & 0.2 & 0.2 & 0.2 & 0.2 \\
& L. sidoides EO & - & 0.1 & 0.05 & - \\
& Clove EO & 0.1 & - & 0.05 & - \\
& Thymol & - & - & - & 0.05 \\
Equenol & - & - & - & 0.05 \\
phase & Ethanol & 31.6 & 31.6 & 31.6 & 31.6 \\
& HP- $\beta$-Cyclodextrin & 2 & 2 & 2 & 2 \\
& L. sidoides EO & - & 0.33 & 0.165 & - \\
& Clove EO & 0.27 & - & 0.135 & - \\
& Thymol & - & - & - & 0.11 \\
& Eugenol & - & - & - & 0.12 \\
& Water & 80.0 & 80.0 & 80.0 & 80.0 \\
\hline
\end{tabular}

\subsection{Preparation of Proliposomes}

Freshly prepared liposomal suspensions were frozen at $-20^{\circ} \mathrm{C}$ for about $12 \mathrm{~h}$ in plastic tubes $(50 \mathrm{~mL})$ and for a further $4 \mathrm{~h}$ at $-80^{\circ} \mathrm{C}$ before freeze-drying (MicroModulyo, Thermo Fisher Scientific, Waltham, MA, USA). Lyophilization time lasted for $72 \mathrm{~h}$. The lyophilized liposomes were stored at $-20^{\circ} \mathrm{C}$ for further analysis and characterization. Figure 1 shows the production scheme of EO loaded carriers. 


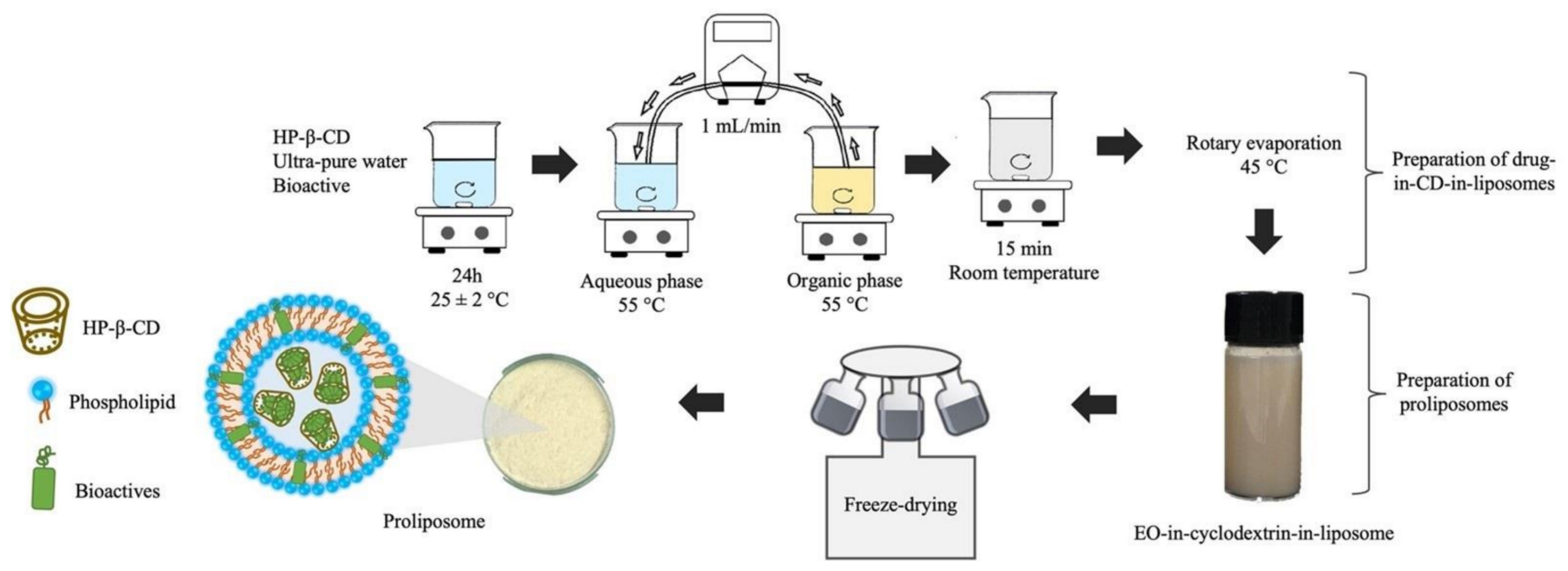

Figure 1. Diagram of EOs-in-cyclodextrin-in-liposome and proliposomes production.

\subsection{Mean Hydrodynamic Diameter, Polydispersity Index, and Zeta Potential}

The mean hydrodynamic diameter and polydispersity index of the EOs-in-cyclodextrinin-liposomes were determined by dynamic light scattering (DLS) using a Zetasizer Nano ZS90 (Malvern, UK). Zeta potential was measured by micro electrophoresis, with the same equipment. All the liquid samples were diluted in MilliQ ${ }^{\circledR}$ water (Millipore, Billerica, MA, USA) at a ratio of $1: 10(\mathrm{v} / \mathrm{v})$ and measured in triplicate at $25^{\circ} \mathrm{C}$. The measurements were repeated on the 1st, 15th, and 30th days after production. For the analysis of proliposomes, these were firstly redispersed in MilliQ ${ }^{\circledR}$ water at the original concentration, stirred for $30 \mathrm{~min}$, and diluted to 1:200 (v/v) before measurements.

\subsection{Differential Scanning Calorimetry}

A differential scanning calorimeter (Shimadzu DSC-50, Shimadzu Corporation, Kyoto, Japan) was used to study the thermal transformations of the components of the formulations and their relationship with particle structure, according to the method described by Zhang et al., with some modifications [27]. Measurements of each component of the formulations, of the physical mixture, and the proliposomes were performed. The samples were exactly weighted in aluminum pans and heated from $20{ }^{\circ} \mathrm{C}$ to $250{ }^{\circ} \mathrm{C}$ following cooling to $20{ }^{\circ} \mathrm{C}$ at a heating and cooling rate of $10^{\circ} \mathrm{C} / \mathrm{min}$.

\subsection{X-ray Diffraction Study}

The X-ray powder diffraction patterns were obtained using a Rigaku Rotaflex RU200B $X$-ray diffractometer (Tokyo, Japan) with $\mathrm{Cu}-\mathrm{K} \alpha$ radiation $(\lambda=1.5418 \AA$ ). Samples were scanned at a current of $100 \mathrm{~mA}$ and a voltage of $50 \mathrm{kV}$. Patterns were obtained using a step width of $1.2^{\circ} / \mathrm{min}$ from $0^{\circ}$ to $50^{\circ}$ at room temperature on a $2 \theta$ scale.

\subsection{Retention of Bioactives}

The amount of the major bioactive compounds (eugenol and thymol) in the liquid and dried products was monitored by high-performance liquid chromatography with diode array detection (HPLC-DAD), following a method previously developed by Leal et al. [28] and validated by our group. Analyses were performed in a Shimadzu HPLC (Shimadzu Corporation, Kyoto, Japan) using a C-18 column (Shimadzu Shim-Pack CLC(M) $4.6 \mathrm{~mm} \times 25 \mathrm{~cm}$, $5 \mu \mathrm{m}, 100 \AA$ ) at an oven temperature of $30^{\circ} \mathrm{C}$, with a volume injection of $20 \mu \mathrm{L}$. The mobile phase used was water $(A)$ and acetonitrile $(B)$ using gradient elution: $0-2$ min $10 \% \mathrm{~B}$ in A; $2-7 \min 10-78 \%$ B in A; 7-17 $\min 78 \% \mathrm{~B}$ in A; 17-20 $\mathrm{min} 78-100 \% \mathrm{~B}$ in A; 20-23 $\min$ $100 \%$ B in A; $23-26$ min $100-10 \%$ B in A; and 23-32 min 10\% B in A. The chromatograms were recorded at $276 \mathrm{~nm}$. The samples were diluted with methanol, homogenized in an ultrasound bath, and kept under magnetic stirring for $30 \mathrm{~min}$. After the extraction, the 
samples were centrifuged for $5 \mathrm{~min}$ at $5000 \times g$ and the supernatants were filtered in a $0.4 \mu \mathrm{m}$ Millipore membrane and analyzed by HPLC.

\subsection{Statistical Analysis}

Results were expressed as mean \pm SD. A two-way analysis of variance (ANOVA) using a Bonferroni post-hoc test was used to compare the levels of significance between the samples and $p<0.05$ was considered statistically significant.

\section{Results and Discussion}

\subsection{Stability Analysis of Liposomes}

For most commercial applications the long-term stability is an important parameter to be considered for a delivery system. We, therefore, carried out a series of tests to evaluate the physicochemical stability of liposomes over one month. The mean hydrodynamic diameter, PDI, and ZP of the liposomal formulations were measured over a storage period of 30 days at $4{ }^{\circ} \mathrm{C}$. The freshly prepared liposomal solutions exhibited a homogeneous whitish appearance. Figure 2 demonstrates the distribution of nanometric and micrometric particles, varying according to the encapsulated bioactive. In general, the systems showed an appreciable increase in the hydrodynamic diameter throughout 30 days of storage at $4{ }^{\circ} \mathrm{C}$, which suggests vesicle coalescence. On the other hand, the liposome formulation containing clove essential oil (CDC) had a mean particle size perceptibly smaller than the other samples. We hypothesized that the differences in particle size are at least partly due to the type of the encapsulated essential oil, because we obtained larger liposomes containing Lippia sidoides essential oil when compared to the liposomes containing clove essential oil, produced by the same method in our pre-formulation studies (data not shown).
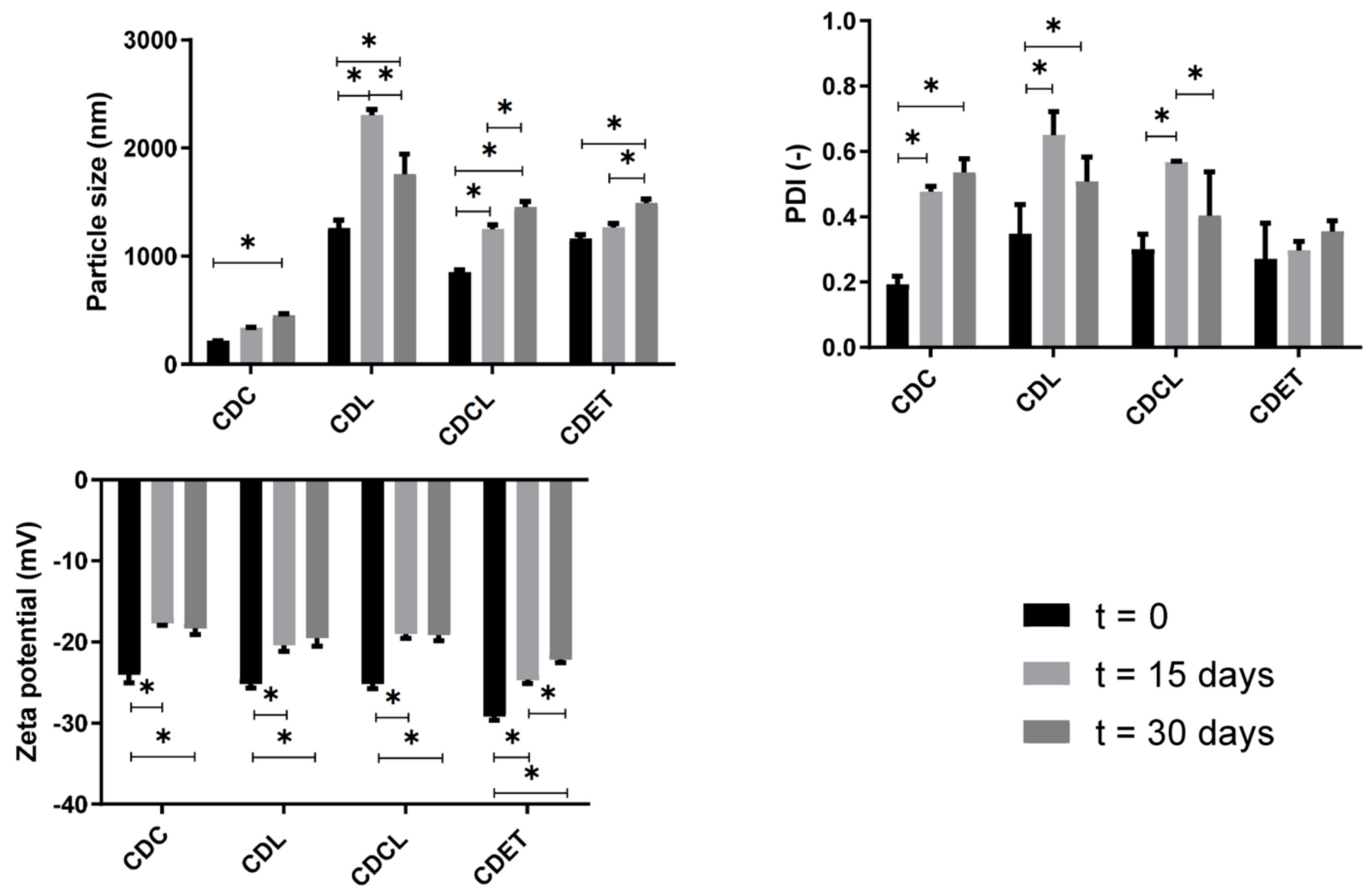

Figure 2. Stability parameters of EOs-in-cyclodextrin-in-liposome systems during storage at $4{ }^{\circ} \mathrm{C}$, at $\mathrm{t}=0$ days, $\mathrm{t}=15$ days, and $\mathrm{t}=30$ days. The symbol $\left({ }^{*}\right)$ means significant difference at $p<0.05$ (Bonferroni post-hoc test). 
The polydispersity index (PDI) was determined to indicate the width of particle size distribution, whose values ranges from 0 (monodisperse system) to 1 (very polydisperse distribution), reflecting the tendency of the particles to aggregate. The PDI values were similar for all the formulations, slightly increasing upon storage. Similar findings were obtained by other authors $[29,30]$, possibly because HP- $\beta-C D$ might replace the drug molecules from the hydrophobic core with cholesterol (or another lipid component), favoring the destabilization of the liposomal structure [31]. This problem is based on a question of affinity of the asset with the HP- $\beta-C D$, the greater the affinity of the bioactive for the $\mathrm{HP}-\beta-\mathrm{CD}$, the more stable the inclusion complex will remain. Therefore, to overcome this problem, the types and concentrations of $\mathrm{CD}$, and the affinity with the drug molecules should be intensively investigated during the pre-formulation studies. The selection of lipids with lower affinity for cyclodextrin than cholesterol or the drug itself should be preferable [31]. As an indicator of vesicle stability, ZP values were reduced over the storage time, corroborating the evidenced changes in particle size and PDI.

\subsection{Proliposomes Properties}

Reconstituted proliposomes were characterized and compared in terms of mean diameter, PDI, and ZP (Table 2). Significant differences were found between the sizes of the liposomal systems. The presence of LEO affected the reconstituted liposomes mean size significantly; CDL and CDET showed similar sizes. PDI was also similar among the developed formulations, slowly increasing from 0.3 to $\approx 0.4$, indicating the relative homogeneity of proliposomes. The $\mathrm{ZP}$ is a parameter linked to the electrostatic repulsion between suspended or emulsified systems and generally is used as indicative of system stability [32]. All formulations showed negative values of zeta potential, ranging from -22.3 to $-26.5 \mathrm{mV}$. Particularly, the larger proliposomes (CDCL) showed significantly higher zeta potential than the others, in agreement with literature results [32].

Table 2. Particle size, PDI, and zeta potential of proliposomes obtained by freeze-drying.

\begin{tabular}{cccc}
\hline Formulation & $\begin{array}{c}\text { Particle Size } \\
(\mathbf{n m})\end{array}$ & $\begin{array}{c}\text { PDI } \\
\mathbf{( - )}\end{array}$ & $\begin{array}{c}\text { Zeta Potential } \\
(\mathbf{m V})\end{array}$ \\
\hline CDC & $354.3 \pm 27.1^{\mathrm{a}}$ & $0.41 \pm 0.05^{+}$ & $-22.3 \pm 0.7^{*}$ \\
CDL & $1648.0 \pm 106.4^{\mathrm{b}}$ & $0.41 \pm 0.05^{\dagger}$ & $-23.3 \pm 0.6^{*}$ \\
CDCL & $3300.3 \pm 476.8^{\mathrm{c}}$ & $0.31 \pm 0.21^{+}$ & $-26.5 \pm 1.3^{* *}$ \\
CDET & $1493.0 \pm 70.6^{\mathrm{b}}$ & $0.29 \pm 0.02^{+}$ & $-23.6 \pm 0.3^{*}$ \\
\hline
\end{tabular}

Same letter $(\mathrm{a}, \mathrm{b}, \mathrm{c})$ or symbols $\left({ }^{*},{ }^{* *},{ }^{+}\right)$means no significant difference according to Bonferroni's multiple comparison test $(p<0.05)$.

Determination of an inclusion complex between host and guest molecule depends on a variety of parameters and requires multivariate analysis for this description. Therefore, complementary characterization methods, including differential scanning calorimetry (DSC) and X-ray diffraction (XRD), were employed to verify the occurrence of complexation. DSC is the most commonly used technique for determining the thermal effects of the material. It quickly provides accurate information on both the physical and energetic properties of the material [33] and indirect evidence about the formation of the cyclodextrin inclusion complex [6]. In this study, DSC was used to study the influence of bioactive compounds on lipid membrane organization.

It is well known that some constituents of the essential oils, among them thymol and eugenol, can increase the fluidity of the liposomal membrane by reducing the phase transition temperature of the phospholipid [34,35]. The DSC analysis of the proliposomes (Figure 3 and Table 3) showed no melting peak of the actives (represented by red or green lines in Figure 3), indicating the absence of any significant level of crystallinity in the analyzed product, confirming its amorphous state. Moreover, the bioactive compounds were able to interact with the phospholipidic membrane, causing variations in the thermodynamic parameters (peak temperature $-T_{m}$ and enthalpy difference $-\Delta H$ ) (Table 3 ). Such variations were more pronounced in proliposomes loading thymol, eugenol, and clove EO. According 
to Cristani et al. [36], these terpenes act as substitutional impurities, causing a decrease in $\mathrm{T}_{\mathrm{m}}$ and $\Delta \mathrm{H}$ values. The disappearance or even gradual decrease of the melting point of a crystalline guest compound provides indirect evidence of the inclusion complex formation with cyclodextrin. However, DSC alone is not a suitable technique to confirm the formation of the cyclodextrin inclusion complex when using volatile substances as guest compounds [37], as the essential oils, thymol, and eugenol. For such guest molecules, X-ray powder diffraction is the most useful technique to detect the inclusion complex formation [20].
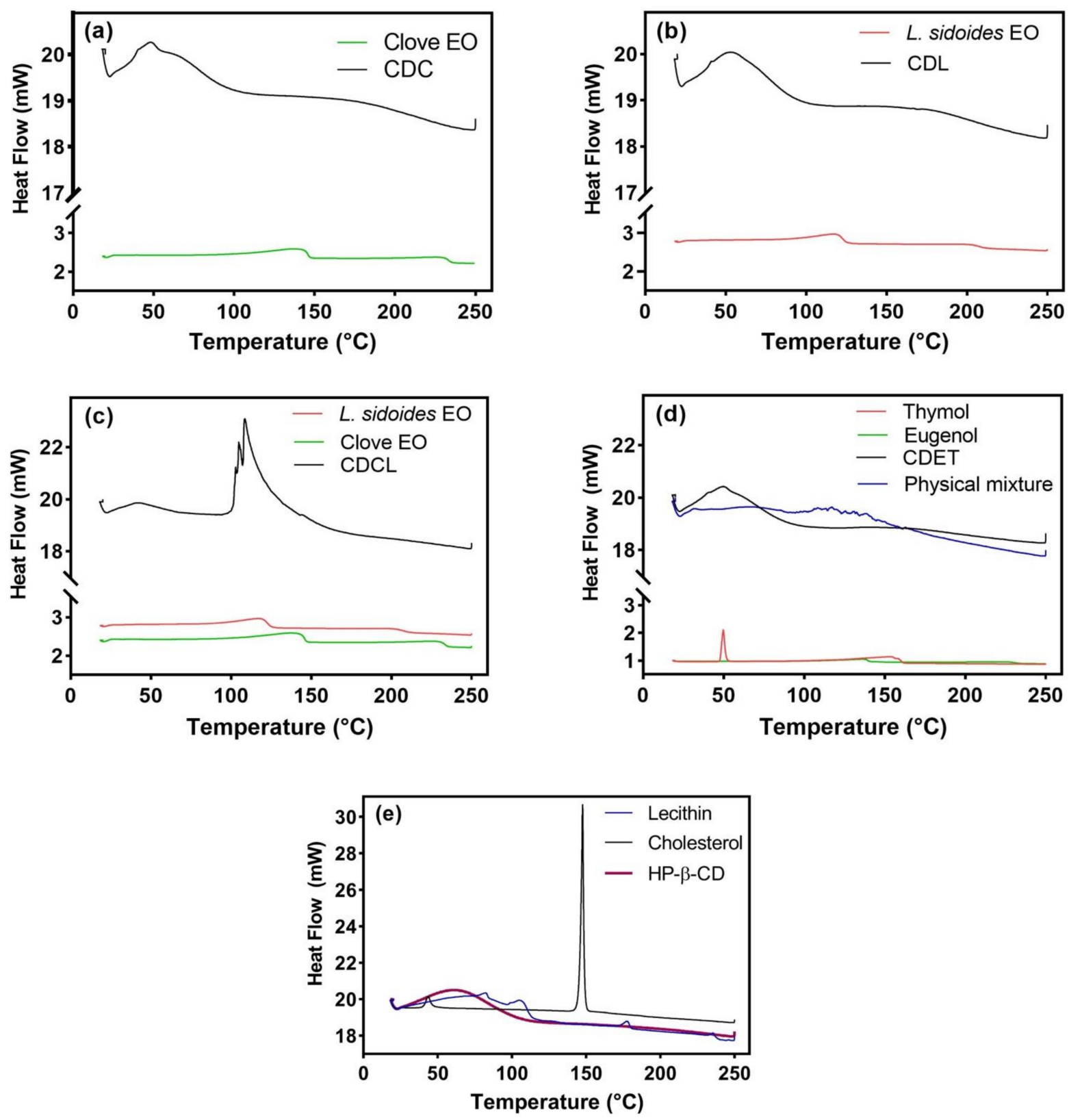

Figure 3. DSC thermograms of proliposomes, essential oils, isolated bioactives, and raw materials: (a) CDC proliposome loaded by clove essential oil and pure clove essential oil; (b) CDL proliposome loaded by L. sidoides essential oil and pure L. sidoides essential oil; (c) CDCL proliposome loaded by both essential oils (L. sidoides and clove), and the pure essential oils; (d) CDET proliposome loaded by both isolated bioactives (thymol and eugenol), the pure isolated bioactives, and physical mixture; (e) bulk raw materials (lecithin, cholesterol, and HP- $\beta-C D$ ). Up: endothermic heat flow. 
Table 3. DSC parameters of proliposomes, bulk materials, bioactive compounds and essential oils.

\begin{tabular}{ccccc}
\hline Sample & $\begin{array}{c}\text { Onset } \\
\left({ }^{\circ} \mathbf{C}\right)\end{array}$ & $\begin{array}{c}\text { Peak } \\
\left({ }^{\circ} \mathbf{C}\right)\end{array}$ & $\begin{array}{c}\Delta \boldsymbol{H} \\
(\mathbf{J} / \mathbf{g})\end{array}$ & $\begin{array}{c}\text { Area } \\
(\mathbf{m} \mathbf{)})\end{array}$ \\
\hline CDC & 32.1 & 48.7 & 80.8 & 177.8 \\
CDL & 31.7 & 54.3 & 93.9 & 197.3 \\
CDCL & 107.1 & 49.9 & 101.5 & 314.8 \\
CDET & 28.0 & 106.5 & 113.2 & 237.7 \\
Lecithin & 97.8 & 147.7 & 12.1 & 31.4 \\
Cholesterol & 145.8 & 63.3 & 67.7 & 148.9 \\
HP- $\beta-C D$ & 23.2 & 136.6 & 160.3 & 368.7 \\
Eugenol & 110.9 & 49.8 & 111.7 & 234.6 \\
Thymol & 47.8 & 117.7 & 125.6 & 314.0 \\
L. sidoides EO & 91.5 & 138.4 & 97.8 & 195.5 \\
Clove EO & 101.5 & & 156.3 & 343.9 \\
\hline
\end{tabular}

X-ray diffraction is also able to characterize and identify the structure of lipid and drug molecules [38]. The X-ray powder diffraction patterns of pure compounds and loaded proliposomes are presented in Figure 4 . The peaks patterns from HP- $\beta$-CD are also present in the samples (CDC, CDL, CDCL, and CDET) and the physical mixture, but are broader and with lower intensity. The addition of guest compounds to the HP- $\beta-C D$ increased the lattice disturbance of the latter, as can be seen by comparing the patterns of the HP- $\beta-C D$ with the proliposomes. This interaction resulted in the appearance of new peaks in the proliposome samples, producing a diffractogram that differs from the one of non-complexed $\mathrm{HP}-\beta-\mathrm{CD}$, evidencing the formation of the inclusion complexes. Concerning lecithin, its main peak was presented in CDC, CDL, and CDET proliposomes, also with a decrease in intensity. The decrease in the intensity of this peak may indicate a change in the crystalline structure of lecithin and a less ordered structure of proliposomes. The broad diffraction peaks also reflect a reduction in crystallinity [6,39]. Such an amorphous state might contribute to the higher retention of bioactives [39]. However, as the diffraction patterns presented by $\mathrm{CDC}, \mathrm{CDL}$, and CDET proliposomes were similar, retention of bioactives in these samples probably also remained similar.

\subsection{Retention of Marker Compounds in Proliposomes}

The content of bioactives in the proliposomes is strongly associated to the previously investigated variables. The results of eugenol and thymol retention in the liposomal structures are shown in Figure 5. The eugenol retention reached near 90\% for liquid samples and $72 \%$ for proliposomes, while for thymol the values were around $80 \%$ for both systems, with no statistical difference between the samples $(p<0.05)$. Indeed, the freezedrying had a significant influence on eugenol retention both for formulations containing essential oil (CDC and CDL) and the isolated bioactives (CDET). Furthermore, the liquid formulations achieved higher eugenol retention in comparison to thymol, but the effect was significantly lower for the dried proliposomes. Similar results for eugenol loss during the freeze-drying of $\beta-C D$ inclusion complexes have also been reported [6]. The relatively higher lipophilicity of thymol suggests favored partitioning both into the lipidic wall of proliposome and the hydrophobic internal cavity of HP- $\beta-C D$, rather than the external hydrophilic surface of the cyclodextrin. Hence, thymol is apparently better incorporated into the lipophilic parts of the delivery system, remaining retained, despite the water removal during the freeze-drying process. Molecular modelling studies could explain the differences between eugenol retention in liquid and proliposomes samples through the arrangement of bioactive molecules inside the $\mathrm{CD}$ cavity. On one hand, the eugenol molecule enters into the $\mathrm{CD}$ cavity from the wider rim, leaving $\mathrm{OH}$ and $\mathrm{MeO}$ groups outside and the allyl group keeps folded towards the phenyl ring [40]. On the other hand, the thymol molecule is located inside the hydrophobic cavity of $\mathrm{CD}$ in a way that allows its $\mathrm{OH}$ group to come close to the hydroxyl groups of $\mathrm{CD}$ to form hydrogen bonds that further stabilize the inclusion complex [41]. Thus, thymol tends to be more stabilized in the 
inclusion complex when compared to eugenol, despite the negative pressure and water removal from the freeze-drying drying process.

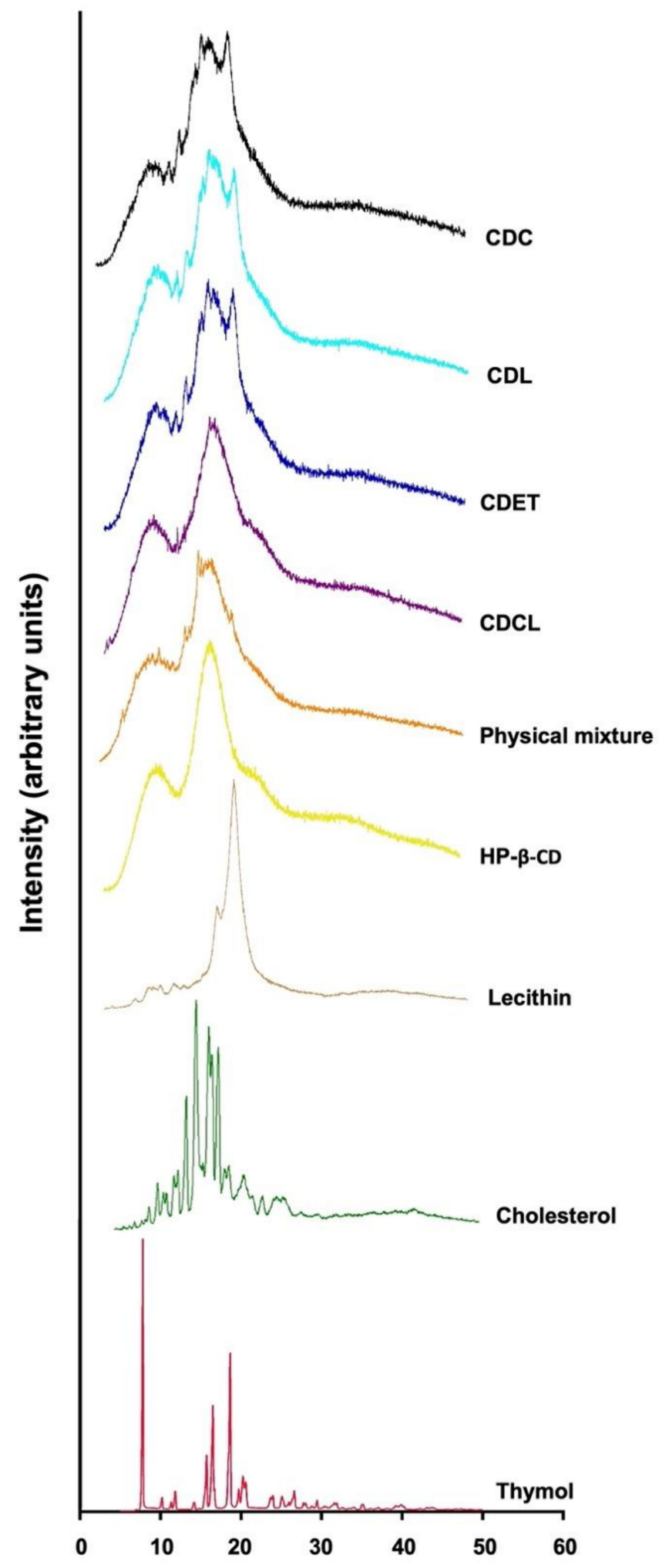

Figure 4. X-ray diffraction (XRD) profiles of proliposomes (CDL, CDCL, CDET), physical mixture (lecithin, cholesterol, HP- $\beta-\mathrm{CD}$, thymol, and eugenol), and bulk raw components. 


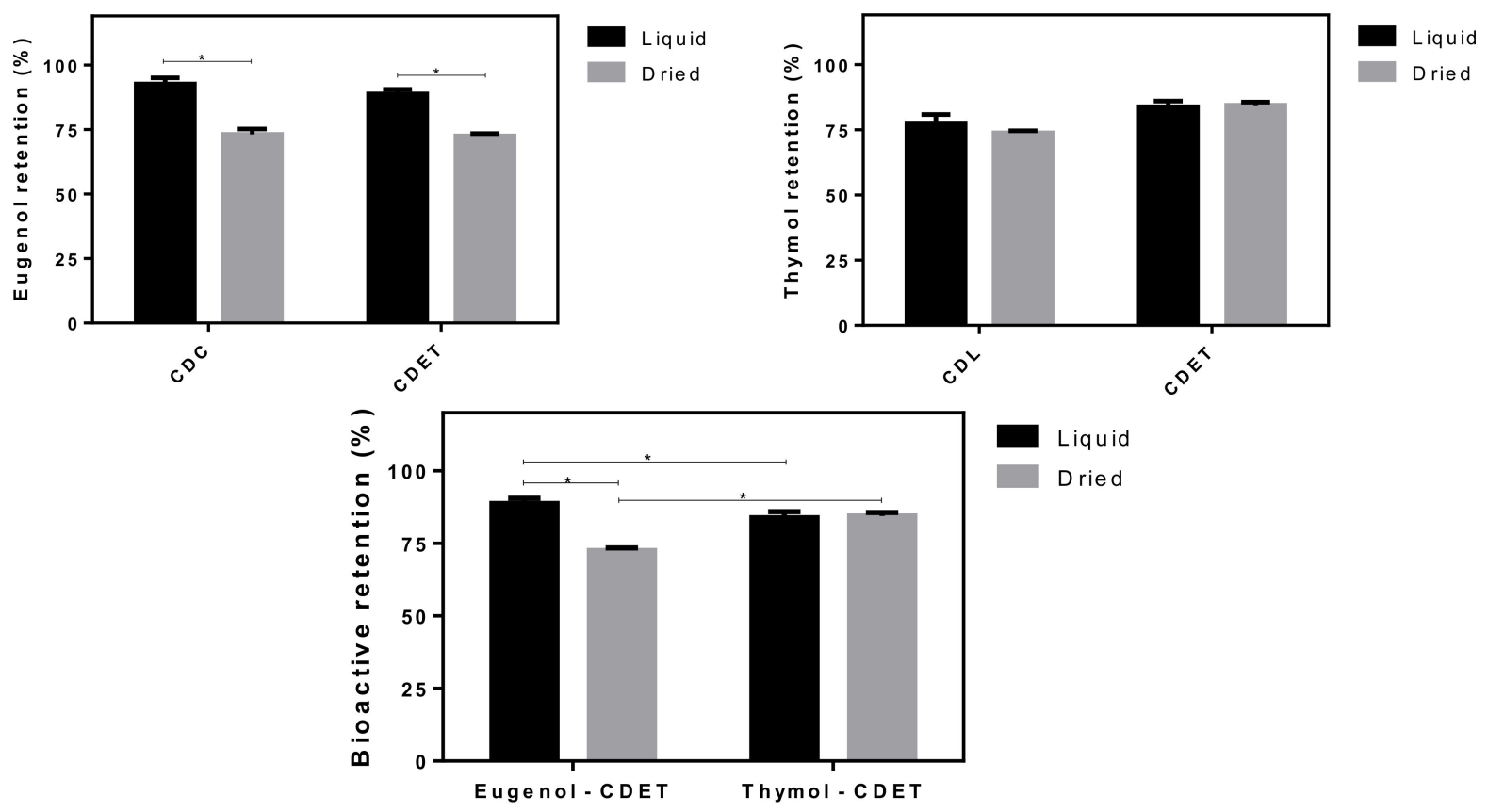

Figure 5. Eugenol and/or thymol retention of liquid and freeze-dried forms of EOs-in-cyclodextrinin-liposome systems. The symbol $\left(^{*}\right)$ means significant difference at $p<0.05$ (Bonferroni post-hoc test).

\section{Conclusions}

Taken together, the results described in the present study allow us to potentially propose drug-in-cyclodextrins-in-liposome as a carrier system to be loaded with Lippia sidoides and/or Syzygium aromaticum EOs, as well as the isolated EOs main compounds eugenol and thymol. With the selected preparation method relatively stable particles and proliposomes have been obtained. The liquid systems and reconstituted composition showed sizes between $350 \mathrm{~nm}$ and $3300 \mathrm{~nm}$ with a low polydispersity index and zeta potential around $-23 \mathrm{mV}$. The samples also presented a low degree of crystallinity and high retention of the major marker compounds (eugenol and thymol). While not compromising the objectives of this study, which have been successfully accomplished, namely the demonstration that our proposed methodology has been successful for the encapsulation of EOs and other natural phytopharmaceutical and volatile compounds in cyclodextrin-in-liposomes, we share the opinion that some additional studies, namely, the assessment of the release and toxicological profiles, including scanning/transmission electron microscopy and Fouriertransformed infrared spectroscopy, as well as the evaluation of the promising biological activity, will certainly add value to the potential use of these systems. Overall, EOs-incyclodextrin-in-liposome has remarkable potential for use in a wide variety of products of food, cosmetic, and pharmaceutical industries.

Author Contributions: Conceptualization, methodology, investigation, writing-original draft preparation, I.B. and A.M.O.; I.B., A.M.O., E.B.S. and W.P.O.; formal analysis, writing-review and editing, visualization, resources, supervision, funding, E.B.S. and W.P.O. All authors have read and agreed to the published version of the manuscript.

Funding: Authors received funding from The State of São Paulo Research Foundation (FAPESP) for sponsorship of the project No. 2018/26069-0; from the Coordination of Superior Level Staff Improvement (CAPES) for the fellowship of the first author. The authors also acknowledge the Portuguese Science and Technology Foundation, Ministry of Science and Education (FCT/MEC) for national funds co-financed by FEDER, under the Partnership Agreement PT2020 for the granted project UIDB/04469/2020 (strategic fund).

Institutional Review Board Statement: Not applicable. 


\section{Informed Consent Statement: Not applicable.}

Data Availability Statement: Data are available from corresponding authors upon request.

Conflicts of Interest: The authors declare no conflict of interest.

\section{References}

1. Baldim, I.; Souza, C.R.F.; Oliveira, W.P. Encapsulation of Essential Oils in Lipid-Based Nanosystems. In Phytotechnology; CRC Press: Boca Raton, FL, USA, 2021; pp. 197-230.

2. Baldim, I.; Tonani, L.; von Zeska Kress, M.R.; Pereira Oliveira, W. Lippia sidoides essential oil encapsulated in lipid nanosystem as an anti-Candida agent. Ind. Crops Prod. 2019, 127, 73-81. [CrossRef]

3. Carbone, C.; Teixeira, M.D.C.; Sousa, M.D.C.; Martins-Gomes, C.; Silva, A.M.; Souto, E.M.B.; Musumeci, T. Clotrimazole-loaded mediterranean essential oils NLC: A synergic treatment of Candida skin infections. Pharmaceutics 2019, 11, 231. [CrossRef] [PubMed]

4. Carbone, C.; Martins-Gomes, C.; Caddeo, C.; Silva, A.M.; Musumeci, T.; Pignatello, R.; Puglisi, G.; Souto, E.B. Mediterranean essential oils as precious matrix components and active ingredients of lipid nanoparticles. Int. J. Pharm. 2018, 548, 217-226. [CrossRef] [PubMed]

5. Hensel, A.; Bauer, R.; Heinrich, M.; Spiegler, V.; Kayser, O.; Hempel, G.; Kraft, K. Challenges at the time of COVID-19: Opportunities and innovations in antivirals from nature. Planta Med. 2020, 86, 659-664. [CrossRef] [PubMed]

6. Campos, E.V.R.; Proença, P.L.F.; Oliveira, J.L.; Melville, C.C.; Della Vechia, J.F.; de Andrade, D.J.; Fraceto, L.F. Chitosan nanoparticles functionalized with $\beta$-cyclodextrin: A promising carrier for botanical pesticides. Sci. Rep. 2018, 8, 2067. [CrossRef]

7. Pandiyan, G.N.; Mathew, N.; Munusamy, S. Larvicidal activity of selected essential oil in synergized combinations against Aedes aegypti. Ecotoxicol. Environ. Saf. 2019, 174, 549-556. [CrossRef]

8. Han, X.; Parker, T.L. Anti-inflammatory activity of clove (Eugenia caryophyllata) essential oil in human dermal fibroblasts. Pharm. Biol. 2017, 55, 1619-1622. [CrossRef]

9. Toscano-Garibay, J.D.; Arriaga-Alba, M.; Sánchez-Navarrete, J.; Mendoza-García, M.; Flores-Estrada, J.J.; Moreno-Eutimio, M.A.; Espinosa-Aguirre, J.J.; González-Ávila, M.; Ruiz-Pérez, N.J. Antimutagenic and antioxidant activity of the essential oils of Citrus sinensis and Citrus latifolia. Sci. Rep. 2017, 7, 11479. [CrossRef]

10. Radünz, M.; da Trindade, M.L.M.; Camargo, T.M.; Radünz, A.L.; Borges, C.D.; Gandra, E.A.; Helbig, E. Antimicrobial and antioxidant activity of unencapsulated and encapsulated clove (Syzygium aromaticum, L.) essential oil. Food Chem. 2019, 276, 180-186. [CrossRef]

11. Zielińska, A.; Ferreira, N.R.; Feliczak-Guzik, A.; Nowak, I.; Souto, E.B. Loading, release profile and accelerated stability assessment of monoterpenes-loaded solid lipid nanoparticles (SLN). Pharm. Dev. Technol. 2020, 25, 832-844. [CrossRef]

12. Zielińska, A.; Ferreira, N.R.; Durazzo, A.; Lucarini, M.; Cicero, N.; El Mamouni, S.; Silva, A.M.; Nowak, I.; Santini, A.; Souto, E.B. Development and Optimization of Alpha-Pinene-Loaded Solid Lipid Nanoparticles (SLN) Using Experimental Factorial Design and Dispersion Analysis. Molecules 2019, 24, 2683. [CrossRef] [PubMed]

13. Teixeira, M.C.; Carbone, C.; Souto, E.B. Beyond liposomes: Recent advances on lipid based nanostructures for poorly soluble/poorly permeable drug delivery. Prog. Lipid Res. 2017, 68, 1-11. [CrossRef] [PubMed]

14. Pashirova, T.N.; Zueva, I.V.; Petrov, K.A.; Lukashenko, S.S.; Nizameev, I.R.; Kulik, N.V.; Voloshina, A.D.; Almasy, L.; Kadirov, M.K.; Masson, P.; et al. Mixed cationic liposomes for brain delivery of drugs by the intranasal route: The acetylcholinesterase reactivator 2-PAM as encapsulated drug model. Colloids Surf. B Biointerfaces 2018, 171, 358-367. [CrossRef] [PubMed]

15. Usach, I.; Margarucci, E.; Manca, M.L.; Caddeo, C.; Aroffu, M.; Petretto, G.L.; Manconi, M.; Peris, J.-E. Comparison between citral and pompia essential oil loaded in phospholipid vesicles for the treatment of skin and mucosal infections. Nanomaterials 2020, 10, 286. [CrossRef]

16. Khan, I.; Yousaf, S.; Subramanian, S.; Korale, O.; Alhnan, M.A.; Ahmed, W.; Taylor, K.M.G.; Elhissi, A. Proliposome powders prepared using a slurry method for the generation of beclometasone dipropionate liposomes. Int. J. Pharm. 2015, 496, 342-350. [CrossRef]

17. Sebaaly, C.; Charcosset, C.; Stainmesse, S.; Fessi, H.; Greige-Gerges, H. Clove essential oil-in-cyclodextrin-in-liposomes in the aqueous and lyophilized states: From laboratory to large scale using a membrane contactor. Carbohydr. Polym. 2016, 138, 75-85. [CrossRef]

18. Angelini, G.; Campestre, C.; Boncompagni, S.; Gasbarri, C. Liposomes entrapping $\beta$-cyclodextrin/ibuprofen inclusion complex: Role of the host and the guest on the bilayer integrity and microviscosity. Chem. Phys. Lipids 2017, 209, 61-65. [CrossRef]

19. Cirri, M.; Mennini, N.; Maestrelli, F.; Mura, P.; Ghelardini, C.; Di Cesare Mannelli, L. Development and in vivo evaluation of an innovative "Hydrochlorothiazide-in Cyclodextrins-in Solid Lipid Nanoparticles" formulation with sustained release and enhanced oral bioavailability for potential hypertension treatment in pediatrics. Int. J. Pharm. 2017, 521, 73-83. [CrossRef]

20. Wadhwa, G.; Kumar, S.; Chhabra, L.; Mahant, S.; Rao, R. Essential oil-cyclodextrin complexes: An updated review. J. Incl. Phenom. Macrocycl. Chem. 2017, 89, 39-58. [CrossRef]

21. Azzi, J.; Auezova, L.; Danjou, P.-E.; Fourmentin, S.; Greige-Gerges, H. First evaluation of drug-in-cyclodextrin-in-liposomes as an encapsulating system for nerolidol. Food Chem. 2018, 255, 399-404. [CrossRef] 
22. Maestrelli, F.; González-Rodríguez, M.L.; Rabasco, A.M.; Ghelardini, C.; Mura, P. New “drug-in cyclodextrin-in deformable liposomes" formulations to improve the therapeutic efficacy of local anaesthetics. Int. J. Pharm. 2010, 395, 222-231. [CrossRef]

23. Muneer, S.; Masood, Z.; Butt, S.; Anjum, S.; Zainab, H.; Anwar, N.; Ahmad, N. Proliposomes as Pharmaceutical Drug Delivery System: A Brief Review. J. Text. Sci. Eng. 2017, 8, 448. [CrossRef]

24. Bankole, V.O.; Osungunna, M.O.; Souza, C.R.F.; Salvador, S.L.; Oliveira, W.P. Spray-dried proliposomes: An innovative method for encapsulation of rosmarinus officinalis L. polyphenols. AAPS PharmSciTech 2020, 21, 143. [CrossRef]

25. Gallez, A.; Palazzo, C.; Blacher, S.; Tskitishvili, E.; Noël, A.; Foidart, J.-M.; Evrard, B.; Pequeux, C.; Piel, G. Liposomes and drug-in-cyclodextrin-in-liposomes formulations encapsulating $17 \beta$-estradiol: An innovative drug delivery system that prevents the activation of the membrane-initiated steroid signaling (MISS) of estrogen receptor $\alpha$. Int. J. Pharm. 2020, $573,118861$. [CrossRef]

26. Gharib, R.; Auezova, L.; Charcosset, C.; Greige-Gerges, H. Drug-in-cyclodextrin-in-liposomes as a carrier system for volatile essential oil components: Application to anethole. Food Chem. 2017, 218, 365-371. [CrossRef]

27. Zhang, L.; Zhang, Q.; Wang, X.; Zhang, W.; Lin, C.; Chen, F.; Yang, X.; Pan, W. Drug-in-cyclodextrin-in-liposomes: A novel drug delivery system for flurbiprofen. Int. J. Pharm. 2015, 492, 40-45. [CrossRef]

28. Leal, L.K.A.M.; Oliveira, V.M.; Araruna, S.M.; Miranda, M.C.C.; Oliveira, F.M.A. Análise de timol por CLAE na tintura de Lippia sidoides Cham. (alecrim-pimenta) produzida em diferentes estágios de desenvolvimento da planta. Rev. Bras. Farmacogn. 2003, 13, 9-11. [CrossRef]

29. Rahman, S.; Cao, S.; Steadman, K.J.; Wei, M.; Parekh, H.S. Native and B-cyclodextrin-enclosed curcumin: Entrapment within liposomes and their in vitro cytotoxicity in lung and colon cancer. Drug Deliv. 2012, 19, 346-353. [CrossRef]

30. Lapenda, T.L.S.; Morais, W.A.; Almeida, F.J.F.; Ferraz, M.S.; Lira, M.C.B.; Santos, N.P.S.; Maciel, M.A.M.; Santos-Magalhães, N.S. Encapsulation of Trans-dehydrocrotonin in liposomes: An enhancement of the antitumor activity. J. Biomed. Nanotechnol. 2013, 9, 499-510. [CrossRef]

31. Chen, J.; Lu, W.-L.L.; Gu, W.; Lu, S.-S.S.; Chen, Z.-P.P.; Cai, B.-C.C.; Yang, X.-X.X. Drug-in-cyclodextrin-in-liposomes: A promising delivery system for hydrophobic drugs. Expert Opin. Drug Deliv. 2014, 11, 565-577. [CrossRef]

32. Isailović, B.D.; Kostić, I.T.; Zvonar, A.; Dordević, V.B.; Gašperlin, M.; Nedović, V.A.; Bugarski, B.M. Resveratrol loaded liposomes produced by different techniques. Innov. Food Sci. Emerg. Technol. 2013, 19, 181-189. [CrossRef]

33. Chountoulesi, M.; Naziris, N.; Pippa, N.; Pispas, S.; Demetzos, C. Differential Scanning Calorimetry (DSC): An Invaluable Tool for the Thermal Evaluation of Advanced Chimeric Liposomal Drug Delivery Nanosystems. In Thermodynamics and Biophysics of Biomedical Nanosystems; Springer: Singapore, 2019; pp. 297-337.

34. Hyldgaard, M.; Mygind, T.; Meyer, R.L. Essential oils in food preservation: Mode of action, synergies, and interactions with food matrix components. Front. Microbiol. 2012, 3, 1-24. [CrossRef] [PubMed]

35. Sherry, M.; Charcosset, C.; Fessi, H.; Greige-Gerges, H. Essential oils encapsulated in liposomes: A review. J. Liposome Res. 2013, 23, 268-275. [CrossRef] [PubMed]

36. Cristani, M.; D’Arrigo, M.; Mandalari, G.; Castelli, F.; Sarpietro, M.G.; Micieli, D.; Venuti, V.; Bisignano, G.; Saija, A.; Trombetta, D. Interaction of four monoterpenes contained in essential oils with model membranes: Implications for their antibacterial activity. $J$. Agric. Food Chem. 2007, 55, 6300-6308. [CrossRef] [PubMed]

37. Fernandes, L.P.; Éhen, Z.; Moura, T.F.; Novák, C.; Sztatisz, J. Characterization of Lippia sidoides oil extract- $\beta$-cyclodextrin complexes using combined thermoanalytical techniques. J. Therm. Anal. Calorim. 2004, 78, 557-573. [CrossRef]

38. Cavendish, M.; Nalone, L.; Barbosa, T.; Barbosa, R.; Costa, S.; Nunes, R.; da Silva, C.F.; Chaud, M.V.; Souto, E.B.; Hollanda, L.; et al Study of pre-formulation and development of solid lipid nanoparticles containing perillyl alcohol. J. Therm. Anal. Calorim. 2020, 141,767-774. [CrossRef]

39. Keivani Nahr, F.; Ghanbarzadeh, B.; Hamishehkar, H.; Samadi Kafil, H.; Nahr, F.K.; Ghanbarzadeh, B.; Hamishehkar, H.; Samadi Kafil, H. Food grade nanostructured lipid carrier for cardamom essential oil: Preparation, characterization and antimicrobial activity. J. Funct. Foods 2018, 40, 1-8. [CrossRef]

40. Locci, E.; Lai, S.; Piras, A.; Marongiu, B.; Lai, A. 13C-CPMAS and1H-NMR Study of the inclusion complexes of $\beta$-cyclodextrin with carvacrol, thymol, and eugenol prepared in supercritical carbon dioxide. Chem. Biodivers. 2004, 1, 1354-1366. [CrossRef]

41. Kfoury, M.; Landy, D.; Ruellan, S.; Auezova, L.; Greige-Gerges, H.; Fourmentin, S. Determination of formation constants and structural characterization of cyclodextrin inclusion complexes with two phenolic isomers: Carvacrol and thymol. Beilstein J. Org. Chem. 2016, 12, 29-42. [CrossRef] 